Article

\title{
Antioxidant Activity of the Extracts of Some Cowpea (Vigna unguiculata (L) Walp.) Cultivars Commonly Consumed in Pakistan
}

\author{
Muhammad Zia-Ul-Haq ${ }^{1}$, Shakeel Ahmad ${ }^{2}$, Ryszard Amarowicz ${ }^{3, *}$ and Vincenzo De Feo ${ }^{4}$ \\ 1 Department of Pharmacognosy, University of Karachi, Karachi-75270, Pakistan; \\ E-Mail: ahirzia@gmail.com \\ 2 Department of Agronomy, Bahauddin Zakariya University, Multan-60800, Pakistan; \\ E-Mail: shakeel.agronomy@gmail.com \\ 3 Institute of Animal Reproduction and Food Research of the Polish Academy of Sciences, \\ Tuwima Str. 10, 10-748 Olsztyn, Poland \\ 4 Department of Pharmaceutical and Biomedical Sciences, Salerno University, Fisciano, \\ 84084 Salerno, Italy; E-Mail: defeo@unisa.it \\ * Author to whom correspondence should be addressed; E-Mail: r.amarowicz@pan.olsztyn.pl; \\ Tel.: +48-895-234-627; Fax: +48-895-240-124.
}

Received: 23 November 2012; in revised form: 28 January 2013 / Accepted: 31 January 2013 / Published: 5 February 2013

\begin{abstract}
The present investigation has been carried out to determine the antioxidant activity of the methanolic extracts obtained from four cultivars of cowpea (Vigna unguiculata (L) Walp.) seeds. Phenolic compounds present in the extracts showed the antioxidant and antiradical properties when investigated using a linoleic acid peroxidation model, FRAP, ORAC and TRAP assays, as well as DPPH, hydroxyl, nitric oxide and superoxide radical scavenging activity. The HPLC analysis of the cowpea extracts showed the presence of neochlorogenic acid, chlorogenic acid and caffeic acids. The results indicated that methanolic extract of the cowpea resembled in the aforementioned activities those from other leguminous seeds and pulses. Phenolic constituents contained in cowpea may have a future role as ingredients in the development of functional foods.
\end{abstract}

Keywords: cowpea; antioxidant potential; phenolic compounds; Pakistan 


\section{Introduction}

Cowpea (Vigna unguiculata (L) Walp.) is one of the most ancient food sources and has probably been used as a crop plant since Neolithic times [1]. Like for many other legumes, its seeds are the most economically valuable plant part of cowpea and are well-known due to their ascribed nutritional and medicinal properties. Known to be an excellent source of protein, cowpea is also rich in important vitamins, minerals, and soluble and insoluble dietary fiber. All parts of cowpea plants are used for food or fodder. The tender shoot tips and leaves are consumed when they reach the seeding stage while immature pods and seeds are consumed during the fruiting stage. Harvested dry seeds can be ground into a slurry to make cowpea cake, or deep fried into bean balls, or the seeds could be boiled, mixed with sauce or stew and consumed directly. Plant residues are used as fodder for farm animals [2]. Cowpea is used in culinary dishes in the Indo-Pakistan sub-continent. The consumption of cowpea seeds, after processing such as soaking, dry heating, followed by cooking along with cooked rice, is a common cuisine among the rural people in Pakistan. Fresh young leaves, immature pods, and seeds are used as vegetables, while dry grain is used to prepare main meal dishes and snacks [3]. The cooking liquor of the seeds with spices is considered to be a potential remedy for the common cold. Leaves are boiled, drained, sun-dried and then stored for later use. Seed oil exhibit antidiabetic properties [4]. Seeds possess nematicidal and antifungal properties [5]. Green cowpea seeds are sometimes roasted like peanuts. The roots are eaten in Sudan and Ethiopia. Scorched seeds are occasionally used as a coffee substitute. The seed is diuretic and after eating after boiling is considered to destroy worms in the stomach [6].

In Pakistan, various varieties of cowpeas are popularly consumed as a source of dietary proteins, while the cultivation and consumption of cowpea is increasing due to recent reports on the their high nutritional qualities. Although some preliminary information has been presented in an earlier report [7], detailed investigations are still required as no report on the antioxidant potential of cowpea indigenous to Pakistan has been presented so far. This study has been conducted to determine the antioxidant properties of the extracts of cowpea to explore its beneficial effects as a potential functional food.

\section{Results and Discussion}

Antioxidants are an important part of the defense system of the human body and help to cope with oxidative stress caused by reactive oxygen species [8]. There is a growing interest in the antioxidant activity of phenolics and condensed tannin contents of plant extracts due to their potential role in disease prevention and health promotion. Estimation of total phenolic contents (TPC) and condensed tannin contents is a common-bench assay and first step used during evaluation of antioxidant activity of plant extracts and natural products isolated therefrom. TPC values (expressed in mg GAE/g) of cowpea seed extracts are presented in Table 1. A wide variation was observed for phenolic contents and the cultivars differed significantly with respect to this parameter. The highest TPC was obtained in the case of White star (19.3 mg GAE/g) whereas the lowest TPC was obtained in the case of CP1 (11.9 mg GAE/g). Our values for total phenolic contents are in partial agreement with those reported by other authors [9] for cowpea. Phenolic contents are comparatively greater than those observed for seed extracts of chickpea and lentil cultivars from Pakistan [10,11]. According to literature data, the total phenolic content is directly associated with antioxidant activity [12,13]. Highest condensed tannin 
contents were observed for White star $(25.4 \mathrm{mg} \mathrm{CE} / \mathrm{g})$ while lowest was observed for CP1 (14.9 $\mathrm{mg}$ $\mathrm{CE} / \mathrm{g}$ ). It is evident that condensed tannin contents are also greater than those of seed extracts of chickpea and lentil from Pakistan. Condensed tannins are located mainly in the testa and play an important role in the defense system of seeds that are exposed to oxidative damage by many environmental factors [14]. It is well-known that phenolic content as well as condensed tannin contents vary depending on several factors such as different genotype, growing condition, agronomic practices employed, season, maturity, post-harvest storage and processing conditions and solvent used for extraction. The results indicate that cowpea seeds are rich in antioxidant activity than chickpea and lentil seed as antioxidant activity is dependent to a large extent on these constituents.

Table 1. Contents of total phenolics and condensed tannins $(\mathrm{mg} / \mathrm{g})$ of the extracts of cowpea seeds.

\begin{tabular}{lcccc}
\hline Contents & CP1 & CP2 & White star & SA dandy \\
\hline Total phenolics & $11.9 \pm 0.2^{\mathrm{c}}$ & $14.0 \pm 0.1^{\mathrm{b}}$ & $19.32 \pm 0.1^{\mathrm{a}}$ & $16.2 \pm 0.1^{\mathrm{b}}$ \\
Condensed tannins & $14.9 \pm 0.2^{\mathrm{c}}$ & $19.2 \pm 0.4^{\mathrm{b}}$ & $25.4 \pm 0.4^{\mathrm{a}}$ & $20.9 \pm 0.6^{\mathrm{b}}$ \\
\hline
\end{tabular}

Mean values in the same row having different letters differ significantly $(p<0.05)$. CP1, CP2, White star and AS dandy are the names of cowpea cultivars.

Due to the complexity of plant phenolics and different reactivity of phenols toward assay reagents, these results should be reinforced by HPLC analysis, currently the most popular and reliable technique for analysis of phenolic compounds. The RP-HPLC chromatograms of cowpea extracts recorded at $320 \mathrm{~nm}$ were characterized by the presence of ten dominant peaks (1-10) with a retention times of 13.1, 15.2, 16.5, 18.6, 20.1, 21.3, 22.9, 23.0, 26.2 and $27.8 \mathrm{~min}$ (Figures 1 and 2), respectively. UV spectra of the compounds (peaks 1-10) exhibited maxima at 312, 326, 314, 316, 326, 316, 328, 332, 332 and $330 \mathrm{~nm}$, respectively. Using original standards compounds 2, 5 and 7 were identified as neochlorogenic, chlorogenic, and caffeic acids. Based on the UV-DAD spectra other compounds were tentatively elucidated as $p$-coumaric and caffeic acid derivatives. The extract of White star was characterized by the highest content of individual phenolic compounds (Table 2). The presence of phenolic acids was reported before for the green and red lentil, chicpea, white bean, adzuki bean, and pea [11,15-20]. Phenolic acids noted in cowpea extract are desirable from nutritional point of view because a positive correlation between the consumption of phenolic-rich foods and a decrease of several chronic diseases has been shown to exist from epidemiological studies [21,22].

Figure 1. HPLC chromatogram of phenolic compounds of extracts of seeds of White star cowpea cultivar recorded at $320 \mathrm{~nm}$.

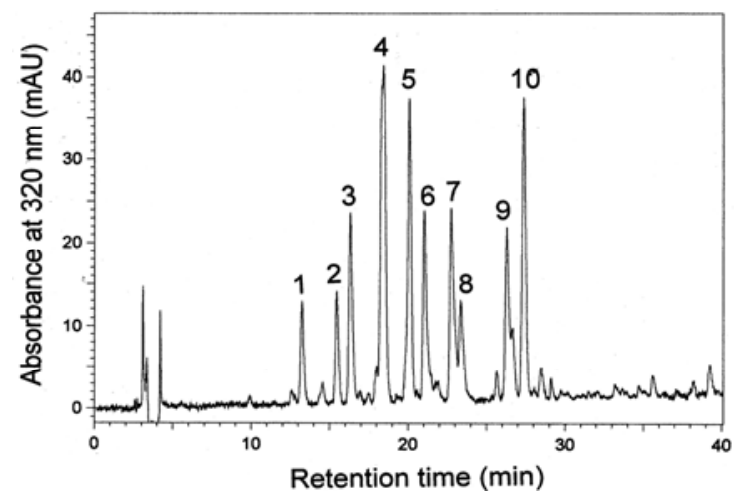


Figure 2. UV-DAD spectra of individual phenolic compounds (numbers of compounds are the same as numbers of peaks mentioned in Figure 1) of extracts of the seeds of White star cowpea cultivar.
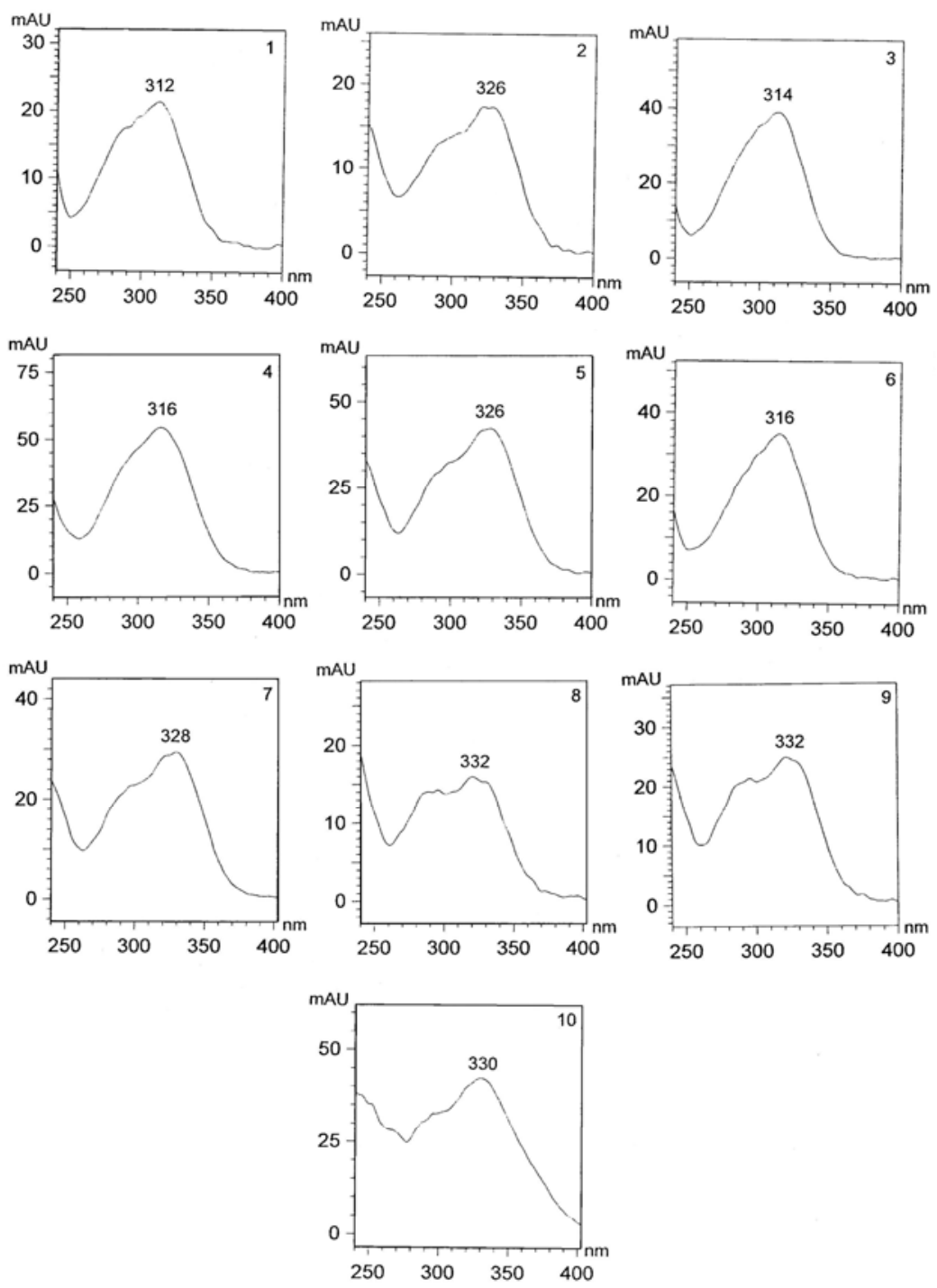

Table 2. Content of individual phenolic compounds in the extracts $(\mathrm{mg} / \mathrm{g})$.

\begin{tabular}{|c|c|c|c|c|}
\hline Compound & CP1 & CP2 & White star & SA dandy \\
\hline 1 & $0.033 \pm 0.002^{b}$ & $0.029 \pm 0.002^{b}$ & $0.060 \pm 0.003^{\mathrm{a}}$ & $0.057 \pm 0.002^{\mathrm{a}}$ \\
\hline 2 (neochlorogenic acid) & $0.127 \pm 0.006^{\mathrm{c}}$ & $0.130 \pm 0.006^{\mathrm{c}}$ & $0.221 \pm 0.010^{\mathrm{a}}$ & $0.178 \pm 0.009^{b}$ \\
\hline 3 & $0.073 \pm 0.003^{c}$ & $0.070 \pm 0.003^{c}$ & $0.120 \pm 0.005^{\mathrm{a}}$ & $0.113 \pm 0.005^{b}$ \\
\hline 4 & $0.161 \pm 0.008^{c}$ & $0.127 \pm 0.006^{\mathrm{d}}$ & $0.245 \pm 0.012^{\mathrm{a}}$ & $0.223 \pm 0.010^{b}$ \\
\hline 5 (chlorogenic acid) & $1.45 \pm 0.07^{\mathrm{d}}$ & $1.79 \pm 0.09^{\mathrm{c}}$ & $2.69 \pm 0.13^{\mathrm{a}}$ & $2.31 \pm 0.12^{b}$ \\
\hline 6 & $0.104 \pm 0.005^{\mathrm{c}}$ & $0.092 \pm 0.003^{\mathrm{d}}$ & $0.121 \pm 0.007^{\mathrm{a}}$ & $0.116 \pm 0.005^{b}$ \\
\hline 7 (caffeic acid) & $0.466 \pm 0.022^{\mathrm{d}}$ & $0.884 \pm 0.042^{\mathrm{a}}$ & $0.602 \pm 0.031^{b}$ & $0.502 \pm 0.028^{c}$ \\
\hline 8 & $0.115 \pm 0.007^{\mathrm{c}}$ & $0.114 \pm 0.005^{\mathrm{c}}$ & $0.302 \pm 0.013^{\mathrm{a}}$ & $0.281 \pm 0.013^{b}$ \\
\hline 9 & $0.278 \pm 0.012^{\mathrm{d}}$ & $0.369 \pm 0.019^{\mathrm{c}}$ & $0.428 \pm 0.020^{a}$ & $0.397 \pm 0.020^{b}$ \\
\hline 10 & $0.355 \pm 0.015^{\mathrm{c}}$ & $0.292 \pm 0.014^{\mathrm{d}}$ & $0.769 \pm 0.035^{\mathrm{a}}$ & $0.674 \pm 0.031^{b}$ \\
\hline
\end{tabular}

Mean values in the same row having different letters differ significantly $(p<0.05)$. Compounds $\mathbf{1}, \mathbf{3}, \mathbf{4}$, and $\mathbf{6}$ were expressed as $p$-coumaric acid; compounds $\mathbf{8 , 9}$ and $\mathbf{1 0}$ as caffeic acid. 
The DPPH radial scavenging assay was used to assess the scavenging activity of cowpea seed extracts as shown in Table 3. $\mathrm{DPPH} \cdot$ is increasingly used for quickly assessing the ability of antioxidants to transfer the labile $\mathrm{H}$ atoms to radicals. The antiradical capacity values of cowpea against DPPH• ranged from 25.1 to $32.5 \mu \mathrm{mol}$ Trolox/g. Our results are close to those reported earlier for cowpea and other food legumes [9-11]. Differences between our results and previous reports may be attributed partly to the differences in the source of materials. The FRAP assay is simple, speedy, inexpensive, and highly reproducible. Antioxidant potential of the cowpea seed extracts was estimated from their ability to reduce TPTZ-Fe ${ }^{3+}$ to TPTZ-Fe ${ }^{2+}$ complex. The FRAP values of the antioxidant extracts from selected cowpea varieties are presented in Table 3. FRAP values of cowpea ranged from 13.2 to $19.4 \mathrm{mmol} \mathrm{Fe}^{2+} / \mathrm{g}$. Our results are different to those reported earlier [9] perhaps due to different units of expressions. The ORAC method is usually employed to estimate antioxidant activity of foods and to evaluate in vivo responses to dietary antioxidant manipulation. The ORAC values ranged from 83.8 to $96.2 \mu \mathrm{mol}$ Trolox/g and are greater than those observed for desi chickpea and lentil from Pakistan [10,11]. Cowpea extract exhibited good antioxidant activity when assessed by linoleic acid peroxidation system (Table 3) and higher antioxidant activity was observed as compared to chickpea seeds [11]. Antioxidant activity of the extracts of leguminous seeds (pea, bean, lentil, faba bean, broad bean, everlasting bean, and chickpea) in a $\beta$-carotene-linoleate model system has been reported in several studies $[13,19,23-26]$. Total antioxidant capacity was observed by TRAP assay. The values reported are different from those observed from values reported for seeds of Capparis deciduas, Lepidium sativum and Ipomoea hederacea from Pakistan [8,27]. The high value of TRAP reported by the mentioned authors was probably by the tannins which were dominating phenolic compounds in the investigated seed extracts.

Table 3. Antioxidant activity of the methanolic extracts of cowpea seeds.

\begin{tabular}{ccccc}
\hline Assay & CP1 & CP2 & White star $^{\text {SA dandy }}$ \\
\hline DPPH $(\mu \mathrm{mol} \mathrm{Trolox} / \mathrm{g})$ & $25.1 \pm 0.6^{\mathrm{b}}$ & $27.9 \pm 0.7^{\mathrm{b}}$ & $32.5 \pm 0.2^{\mathrm{a}}$ & $28.2 \pm 0.4^{\mathrm{b}}$ \\
FRAP $(\mathrm{mmol} \mathrm{Fe} / \mathrm{g})$ & $15.5 \pm 0.2^{\mathrm{b}}$ & $13.2 \pm 0.4^{\mathrm{b}}$ & $19.4 \pm 0.2^{\mathrm{a}}$ & $18.0 \pm 0.6^{\mathrm{a}}$ \\
ORAC $(\mu \mathrm{mol} \mathrm{Trolox} / \mathrm{g})$ & $86.7 \pm 1.2^{\mathrm{b}}$ & $83.8 \pm 1.0^{\mathrm{b}}$ & $96.2 \pm 0.9^{\mathrm{a}}$ & $89.7 \pm 1.4^{\mathrm{b}}$ \\
Inhibition of linoleic acid peroxidation $(\%)$ & $88.1 \pm 2.0^{\mathrm{c}}$ & $93.4 \pm 1.8^{\mathrm{ab}}$ & $96.6 \pm 2.3^{\mathrm{a}}$ & $90.2 \pm 1.5^{\mathrm{bc}}$ \\
TRAP $(\mu \mathrm{mol}$ Trolox/g) & $65.6 \pm 1.1^{\mathrm{c}}$ & $73.0 \pm 0.9^{\mathrm{b}}$ & $87.3 \pm 1.2^{\mathrm{a}}$ & $77.6 \pm 0.3^{\mathrm{b}}$ \\
\hline
\end{tabular}

Mean values in the same row having different letters differ significantly $(p<0.05)$.

Extracts of seeds were assessed for their potential scavenging antiradical activity against some common radicals like hydroxyl, nitric oxide and superoxide and values expressed as $\mathrm{IC}_{50} \mu \mathrm{g} / \mathrm{mL}$. Hydroxyl radical is an extremely reactive free radical formed in biological systems and a highly damaging species in free radical pathology as it may damage almost every molecule found in living cells [28]. This radical may join nucleotides in DNA and cause strand breakage which contributes to carcinogenesis, mutagenesis and cytotoxicity [29]. Hydroxyl radical scavenging capacity of an extract is directly related to its antioxidant activity [30]. The extracts exhibited significant hydroxyl radical scavenging activity (Table 4) with $\mathrm{IC}_{50}$ from 80.6 to $92.4 \mu \mathrm{g} / \mathrm{mL}$ for White star and CP1 respectively. Nitric oxide has an unpaired electron, hence is a free radical nitric oxide. Plant extracts and natural products isolated may counteract the ill-effect of nitric oxide in vivo [31]. The superoxide radical scavenging assay is said to be more relevant than those methods described above, because it utilizes a 
biologically relevant radical source. This radical mediates inflammatory tissue injuries in ischemiareperfusion, arthritis, gout and gastric ulceration. Superoxide radical has a low reactivity and a low capacity to penetrate the lipidic membrane layer, but it can generate hydrogen peroxide and highly reactive hydroxyl radical, via Haber-Weiss reaction [27]. The extracts exhibited significant superoxide radical scavenging activity (Table 4).

Table 4. Antiradical activity $\left[\mathrm{IC}_{50}(\mu \mathrm{g} / \mathrm{mL})\right]$ of the extracts of cowpea seeds.

\begin{tabular}{lcccc}
\hline Scavenging activity & CP1 & CP2 & White star & SA dandy \\
\hline Against hydroxyl radical & $92.4 \pm 1.1^{\mathrm{a}}$ & $84.3 \pm 0.2^{\mathrm{b}}$ & $80.6 \pm 0.4^{\mathrm{c}}$ & $86.5 \pm 1.0^{\mathrm{b}}$ \\
Against nitric oxide radical & $138 \pm 2^{\mathrm{a}}$ & $125 \pm 1^{\mathrm{b}}$ & $108 \pm 0.4^{\mathrm{d}}$ & $113 \pm 1.0^{\mathrm{c}}$ \\
Against superoxide radical & $112 \pm 1^{\mathrm{a}}$ & $103 \pm 1^{\mathrm{b}}$ & $91.2 \pm 0.9^{\mathrm{d}}$ & $97.0 \pm 1.4^{\mathrm{c}}$ \\
\hline
\end{tabular}

Mean values in the same row having different letters differ significantly $(p<0.05)$.

According to literature data the antiradical activities of leguminous extracts were investigated using an EPR spin trapping method [32] enhanced chemiluminescence and photoluminescence [33,34], scavenging of AMVN radical [35], ABAP radical [36], DPPH radical [15-17,37], ABTS cation radical [15-17,37], superoxide anion radical [38] peroxyl radical [36,37].

\section{Experimental}

\subsection{Plant Material and Chemicals}

Seeds of four cowpea cultivars CP1, CP2, White star and AS dandy (1 kg for each cultivar) were procured from the Department of Agronomy, Bahauddin Zakariya University, Multan, Pakistan. Seeds were stored in stainless-steel containers at $4{ }^{\circ} \mathrm{C}$ prior to analysis. All solvents used were of HPLC or analytical grade unless otherwise specified. Ferric chloride, ferrous chloride, ammonium thiocyanate, deoxyribose, trichloroacetic acid (TCA), (+)-catechin, gallic acid, chlorogenic acid, caffeic acid, p-coumaric acid, vanillin, fluorescein, 2,2-azobis(2-amidinopropane) dihydrochloride (ABAP), EDTA, butylated hydroxyanisole (BHA), ascorbic acid, Folin and Ciocalteu's phenol reagent, 2,2-diphenyl-1picrylhydrazyl radical (DPPH'), 2,2'-azinobis-(3-ethylbenzothiazoline-6-sulfonic acid) (ABTS), 6-hydroxy-2,5,7,8-tetramethyl-chroman-2-carboxylic acid (Trolox), 2,4,6-tris(pyridyl-s-triazne (TPTZ), sulphanilamide, $N$-(1-naphthyl) ethylenediamine dihydrochloride, sodium nitroprusside, linoleic acid, R-phycoerythrin were acquired from Sigma-Aldrich (St. Louis, MO, USA). Neochlorogenic acid was purchased from Extrasynthese (Genay Cedex, France).

\subsection{Extraction}

The seeds ( $1 \mathrm{~kg}$ for each cultivar) were ground into flour with an IKA® All Basic mill (IKA Works Inc., Wilmington, NC, USA) and passed through a 60-mesh sieve. The flour was macerated with aqueous methanolic mixture $(5 \mathrm{~L}, 80: 20 ; \mathrm{v} / \mathrm{v})$, at room temperature for fifteen days with occasional shaking. The process was repeated three times with same quantity of solvent mixture. The extracts obtained were combined, filtered through filter paper under vacuum and concentrated under reduced pressure on a rotary evaporator (model Q-344B-Quimis, Sao Paulo, Brazil) using a warm water bath 
(model Q-214M2-Quimis) at $37{ }^{\circ} \mathrm{C}-40{ }^{\circ} \mathrm{C}$, to obtain a thick gummy mass, which was further dried in a desiccator and stored in air-tight vial till further use.

\subsection{Total Phenolics and Condensed Tannins Contents}

The content of total phenolic compounds in extracts was estimated using the Folin and Ciocalteau's phenol reagent [39]. According to Heimler et al. [40] and $\mathrm{Xu}$ and Chang [41], gallic acid was used as a standard in this work and results were reported as $\mathrm{mg}$ gallic acid equivalents $(\mathrm{GAE}) / \mathrm{g}$. Condensed tannins (proanthocyanidins) were analyzed using acidified vanillin reagent [42] and results were expressed as mg catechin equivalents $(\mathrm{CE}) / \mathrm{g}$.

\subsection{RP-HPLC}

For the RP-HPLC finger print analysis of phenolic compounds present in the extracts a Shimadzu system (Shimadzu Corp., Kyoto, Japan) consisting of two LC-10AD pumps, SCTL 10 A system controller, SPD-M 10 A photo-diode array detector, and a prepacked LUNA C $18(4 \times 259 \mathrm{~mm}, 5 \mu \mathrm{m}$, Phenomenex) was used. A flow rate $1 \mathrm{~mL} / \mathrm{min}$, and gradient elution of acetonitrile-water-acetic acid $(5: 93: 2, \mathrm{v} / \mathrm{v} / \mathrm{v})$ [solvent A] and of acetonitrile-water-acetic acid (40:58:2, v/v/v) [solvent B], 0-50 min solvent B from $0 \%$ to $100 \%$ was used [43]. Concentration of sample dissolved in methanol was $10 \mathrm{mg} / \mathrm{mL}$; injection volume $20 \mu \mathrm{L}$; separation of compounds was monitored at 280 and $320 \mathrm{~nm}$.

\subsection{DPPH Radical Scavenging Activity}

$\mathrm{DPPH}^{*}$ scavenging activity of cowpea extracts was evaluated according to the method described earlier [44]. The absorbance of the sample was measured using an UV 160 spectrophotometer, (Shimadzu, Kyoto, Japan) at $517 \mathrm{~nm}$ against ethanol blank. A negative control was taken after adding $\mathrm{DPPH}^{\bullet}$ solution to $0.2 \mathrm{~mL}$ of the respective extraction solvent. Antiradical activity was calculated from equation:

$$
\text { Antiradical activity } \%=\left(1-\frac{\text { Absorbance }_{\text {sample }}}{\text { Absorbance }_{\text {control }}}\right) \times 100
$$

Results were expressed as micromoles of Trolox equivalent per gram of extraxt ( $\mu$ mol Trolox/g) from the tests of the triplicate extracts using the calibration curve of Trolox. Linearity range of the calibration curve was 20 to $1,000 \mu \mathrm{M}$ (r 0.99 ).

\subsection{Ferric-Reducing Antioxidant Power (FRAP) Assay}

The FRAP assay was performed as described by Benzie and Strain [45]. The sample solution analyzed was first properly diluted with deionized water to fit within the linearity range of $\mathrm{Fe}^{2+}$. FRAP value was expressed as mmol of $\mathrm{Fe}^{2+}$ equivalents per $\mathrm{g}$ of extract using the calibration curve of $\mathrm{Fe}^{2+}$. Linearity range of the calibration curve was 0.1 to $1.0 \mathrm{mM}(r=0.99)$. 


\subsection{Oxygen Radical-Absorbing Capacity (ORAC) Assay}

Hydrophilic ORAC assay was carried out on a Gemini EM microplate spectrofluorometer (Molecular Devices, Sunnyvale, CA, USA), which was equipped with an incubator and wavelength adjustable fluorescence filters. The procedures were based on the previous reports [46,47]. The kinetics of the fluorescence was recorded immediately by the software SoftMax Pro (Molecular Devices). The final ORAC values were calculated using a linear equation between the trolox standards or sample concentration and net area under the fluorescein decay curve. The data were analyzed using Microsoft Excel (Microsoft, Roselle, IL, USA). The area under the curve (AUC) was calculated as: $\mathrm{AUC}=0.5+(\mathrm{R} 2 / \mathrm{R} 1+\mathrm{R} 3 / \mathrm{R} 1+\mathrm{R} 3 / \mathrm{R} 1+\ldots+0.5 \mathrm{Rn} / \mathrm{R} 1)$, where $\mathrm{R} 1$ was the fluorescence reading at the initiation of the reaction and $\mathrm{Rn}$ was the last measurement. The net AUC was obtained by subtracting the AUC of the blank from that of a sample or standard. The ORAC value was calculated and expressed as mmol of TE/g of extract using the calibration curve of Trolox. The linearity range of the calibration curve was 5.0 to $50 \mathrm{mM}$ ( $\mathrm{r}$ 0.99). For each specific sample, triplicate extractions were analyzed.

\subsection{Total Radical-Trapping Antioxidant Potential (TRAP) Assay}

The TRAP was determined according to previously reported method based on the protection provided by antioxidants on the fluorescence decay of $(R)$-phycoerythrin (lag-phase) during a controlled peroxidation reaction [48]. The reaction mixture consisted of sample $(120 \mu \mathrm{L})$, phosphate buffer ( $\mathrm{pH} 7.4 ; 2.4 \mathrm{~mL})$, bidistilled water $(375 \mu \mathrm{L})$, diluted R-PE $(30 \mu \mathrm{L})$ and $75 \mu \mathrm{L}$ of 2,2-azobis(2amidinopropane) dihydrochloride (ABAP); the reaction kinetics at $38{ }^{\circ} \mathrm{C}$ were recorded for $45 \mathrm{~min}$ $\left(\lambda_{\text {ex }} 495 \mathrm{~nm}, \lambda_{\text {em }} 570 \mathrm{~nm}\right.$ ) by a LS-55 luminescence spectrometer (Perkin Elmer, Wellesley, MA, USA). TRAP values were calculated from the length of the lag-phase produced by extract and compared with that of Trolox and expressed as $\mu \mathrm{mol}$ of Trolox per $\mathrm{g}$ of extract.

\subsection{Hydroxyl Radical Scavenging Activity}

The hydroxyl radical scavenging capacity was measured using modified method as described previously [49]. The assay was performed by adding EDTA $(0.1 \mathrm{~mL} ; 1 \mathrm{mM}), \mathrm{FeCl}_{3}(0.01 \mathrm{~mL} ; 10 \mathrm{mM})$, $\mathrm{H}_{2} \mathrm{O}_{2}(0.1 \mathrm{~mL} ; 10 \mathrm{mM})$, deoxyribose $(0.36 \mathrm{~mL} ; 10 \mathrm{mM}), 1.0 \mathrm{~mL}$ extract $(20-200 \mu \mathrm{g} / \mathrm{mL})$, phosphate buffer $(0.33 \mathrm{~mL} ; 50 \mathrm{mM} ; \mathrm{pH} 7.4)$ and ascorbic acid $(0.1 \mathrm{~mL})$ in sequence. After ambient incubation, for $1 \mathrm{~h}$, about $1.0 \mathrm{~mL}$ portion of the incubated mixture was mixed with $1.0 \mathrm{~mL}$ of TCA $(10 \%, \mathrm{v} / \mathrm{v})$ and $1.0 \mathrm{~mL}$ of $(0.5 \%)$ TBA (in $0.025 \mathrm{M} \mathrm{NaOH}$ containing $0.025 \mathrm{M} \mathrm{NaOH}$ BHA) to develop the pink chromogen measured at $532 \mathrm{~nm}$. The hydroxyl radical scavenging activity of the extract was reported as the percentage of inhibition of deoxyribose degradation and was calculated according to the following equation:

$$
\text { Inhibition }(\%)=\frac{A_{0}-A_{1}}{A_{0}} \times 100
$$

where $A_{0}$ - absorbance of the control and $A_{1}$ - absorbance of the extract. Ascorbic acid was used as a positive control and results expressed as $\mathrm{IC}_{50}$. 


\subsection{Superoxide Radical Scavenging Activity}

This activity was measured as described by Sabu and Ramadasan [50]. Test solutions of extract (20-200 $\mu \mathrm{g} / \mathrm{mL})$ were taken in a test tube. To this, reaction mixture consisting of sodium carbonate $(1 \mathrm{~mL}$; $50 \mathrm{mM})$, NBT $(0.4 \mathrm{~mL} ; 24 \mathrm{mM})$ and EDTA solutions $(0.2 \mathrm{~mL} ; 0.1 \mathrm{mM})$ were added to the test tube and immediate reading was taken at $560 \mathrm{~nm}$. About $0.4 \mathrm{~mL}$ of hydroxylamine hydrochloride $(1 \mathrm{mM})$ was added to initiate the reaction then reaction mixture was incubated at $25{ }^{\circ} \mathrm{C}$ for 15 min and reduction of NBT was measured at $560 \mathrm{~nm}$. Ascorbic acid was used as the reference compound. Decreased absorbance of the reaction mixture indicates increased superoxide anion scavenging activity. The percentage of inhibition was calculated according to the following equation:

$$
\text { Inhibition }(\%)=\frac{A_{0}-A_{1}}{A_{0}} \times 100
$$

where $\mathrm{A}_{0}$ - absorbance of the control and $\mathrm{A}_{1}$ - absorbance of the extract. Ascorbic acid was used as a positive control and results expressed as $\mathrm{IC}_{50}$.

\subsection{Nitric Oxide Scavenging Activity}

Nitric oxide scavenging activity was measured spectrophotometrically [51]. Sodium nitroprusside $(5 \mathrm{mM})$ in phosphate buffered saline was mixed with different concentrations of the extract $(3 \mathrm{~mL}$; $20-200 \mu \mathrm{g} / \mathrm{mL}$ ) dissolved in methanol and incubated at ambient conditions. After $30 \mathrm{~min}, 1.5 \mathrm{~mL}$ of the incubated solution was removed and diluted with $1.5 \mathrm{~mL}$ of Griess reagent $(1 \%$ sulphanilamide, $2 \%$ phosphoric acid and $0.1 \% N$-(1-naphthyl)ethylenediamine dihydrochloride). The absorbance of the chromophore formed during diazotization of the nitrite with sulphanilamide and subsequent coupling with $\mathrm{N}$-(1-naphthyl)ethylenediamine dihydrochloride was measured at $546 \mathrm{~nm}$ and percentage scavenging activity was measured with reference to standard by following equation:

$$
\text { Inhibition }(\%)=\frac{A_{0}-A_{1}}{A_{0}} \times 100
$$

where $\mathrm{A}_{0}$ - absorbance of the control and $\mathrm{A}_{1}$ - absorbance of the extract. Ascorbic acid was used as a positive control and results expressed as $\mathrm{IC}_{50}$.

\subsection{Antioxidant Activity in Linoleic Acid System}

The antioxidant activity of sample extracts was determined following the method of Osawa and Namiki [52]. Sample extracts were added to a solution mixture of linoleic acid $(0.13 \mathrm{~mL}), 99.8 \%$ ethanol $(10 \mathrm{~mL})$ and $0.2 \mathrm{M}$ sodium phosphate buffer $(\mathrm{pH} 7.0,10 \mathrm{~mL})$. The total volume was adjusted to $25 \mathrm{~mL}$ with distilled water. The solution was incubated at $40{ }^{\circ} \mathrm{C}$ for $360 \mathrm{~h}$ and the degree of oxidation was measured according to the thiocyanate method [53] with $10 \mathrm{~mL}$ of ethanol (75\%; v/v), $0.2 \mathrm{~mL}$ of an aqueous solution of ammonium thiocyanate $(30 \% ; \mathrm{m} / \mathrm{v}), 0.2 \mathrm{~mL}$ sample solution and $0.2 \mathrm{~mL}$ of ferrous chloride $\left(\mathrm{FeCl}_{2}\right)$ solution $(20 \mathrm{mM}$ in $3.5 \%[\mathrm{~m} / \mathrm{v}] \mathrm{HCl})$ being added sequentially. After $3 \mathrm{~min}$ of stirring, the absorption values of mixtures measured at $500 \mathrm{~nm}$ were taken as peroxide contents. A control was performed with linoleic acid but without the extracts. Synthetic antioxidants BHA and 
BHT were used as the positive controls. The percent inhibition of linoleic acid peroxidation to express antioxidative activity was calculated from the equation

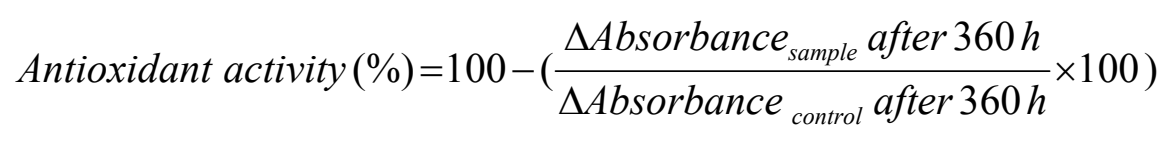

\subsection{Statistical Analysis}

All analyses were performed in triplicate and values expressed as the mean \pm standard deviation. Data analysis was carried out using the analysis of variance and Tukey's post-hoc test.

\section{Conclusions}

Although cowpea seeds are increasingly consumed as human food in Pakistan, the beneficial effects of their bioactive compounds remain largely unexplored. The assessment of antioxidant potential might be a fruitful approach for advocating them as nutraceuticals, in addition to them being potential protein and carbohydrate sources. The consumption of a processed cowpea would not only improve nutrient utilization, but also provide potential nutraceuticals for human health. It could therefore be concluded that cowpea could contribute significantly in the management and/or prevention of degenerative diseases associated with free radical damage, in addition to their traditional role of preventing protein malnutrition.

\section{References}

1. Summerfield, R.J.; Huxley, P.A.; Steelle, W. Cowpea (Vigna unguiculata L. Walp). Field Crop Abstr. 1974, 27, 301-312.

2. Fery, R.L. New Opportunities in Vigna. In Trends in New Crops and New Ideas; Jamik, J., Whipkey, A., Eds.; ASHS Press: Alexandria, VA, USA, 2000; pp. 424-428.

3. Quin, F.M. Introduction. In Advances in Cowpea Research; Singh, B.B., Raj, D.R.M., Dushiell, K.E., Jackai, L.E.N., Eds.; Copublication of International Institute of Tropical Agriculture (IITA) and Japan International Research Center for Agricultural Sciences (JIRCAS), IITA: Ibadan, Nigeria, 1997.

4. Ashraduzzaman, M.; Alam, M.A.; Khatun, S.; Banu, S.; Absar, N. Vigna unguiculata linn. Walp. seed oil exhibiting antidiabetic effects in alloxan induced diabetic rats. Mal. J. Pharm. Sci. 2011, 9, 13-23.

5. Ahmad, S.; Akhter, M.; Zia-Ul-Haq, M.; Mehjabeen, A.S. Antifungal and nematicidal activity of selected legumes of Pakistan. Pak. J. Bot. 2010, 42, 1327-1331.

6. Chopra, R.N.; Nayar, S.L.; Chopra, I.C. Glossary of Indian Medicinal Plants (Including the Supplement); Council of Scientific and Industrial Research: New Delhi, India, 1986.

7. Zia-Ul-Haq, M.; Ahmad, S.; Chiavaro, E.; Mehjabeen; Ahmed, S. Studies of oil from cowpea (Vigna unguiculata (L) walp.) cultivars commonly grown in Pakistan. Pak. J. Bot. 2010, 42, 1333-1341. 
8. Zia-Ul-Haq, M.; Ahmad, S.; Calani, L.; Mazzeo, T.; Del Rio, D.; Pellegrini, N.; de Feo, V. Compositional study and antioxidant potential of Ipomoea hederacea Jacq. and Lepidium sativum L. seeds. Molecules 2012, 17, 10306-10321.

9. Siddhuraju, P.; Becker, K. The antioxidant and free radical scavenging activities of processed cowpea (Vigna unguiculata (L.) Walp.) seed extracts. Food Chem. 2007, 101, 10-19.

10. Zia-Ul-Haq, M.; Ahmad, S.; Iqbal, S.; Luthria, D.L.; Amarowicz, R. Antioxidant potential of lentil cultivars commonly consumed in Pakistan. Oxid. Comm. 2011, 34, 819-831.

11. Zia-Ul-Haq, M.; Iqbal, S.; Ahmad, S.; Bhanger, M.I.; Wiczkowski, W.; Amarowicz, R. Antioxidant potential of desi chickpea varieties commonly consumed in Pakistan. J. Food Lipids 2008, 15, 326-342.

12. Awika, J.M.; Rooney, L.W.; Wu, X.; Prior, R.L.; Zevallos, L.C. Screening methods to measure antioxidant activity of sorghum (Sorghum bicolor) and sorghum products. J. Agric. Food Chem. 2003, 51, 6657-6662.

13. Amarowicz, R.; Troszynska, A.; Barylko-Pikielna, N.; Shahidi, F. Extracts of polyphenolics from legume seeds - correlation between their total antioxidant activity, total phenolics content, tannins content and astringency. J. Food Lipids 2004, 11, 278-286.

14. Troszynska, A.; Estrella, I.; López-Amóres, M.L.; Hernóndez, T. Antioxidant activity of pea (Pisum sativum L.) seed coat acetone extract. LWT-Food Sci. Technol. 2002, 35, 158-164.

15. Amarowicz, R.; Estrella, I.; Hernández, T.; Dueñas, M.; Troszynska, A.; Kosinska, A.; Pegg, R.B. Antioxidant activity of a red lentil extract and its fractions. Int. J. Mol. Sci. 2009, 10, 5513-5527.

16. Amarowicz, R.; Estrella, I.; Hernández, T.; Robredo, S.; Troszyńska, A.; Kosińska, A.; Pegg, R.B. Free radical-scavenging capacity, antioxidant activity, and phenolic composition of green lentil (Lens culinaris). Food Chem. 2010, 121, 705-711.

17. Karamać, M.; Amarowicz, R.; Weidner, S.; Shahidi, F. Antioxidative activity of phenolic fractions of white bean (Phaseolus vulgaris L.). J. Food Lipids 2004, 11, 165-177.

18. Amarowicz, R.; Estrella, I.; Hernández, T.; Troszyńska, A. Antioxidant activity of extract of adzuki bean and its fractions. J. Food Lipids 2008, 15, 119-136.

19. Amarowicz, R.; Troszynska, A. Antioxidant activity of extract of pea and its fractions of low molecular phenolics and tannins. Pol. J. Food Nutr. Sci. 2003, 12, 10-15.

20. Amarowicz, R.; Karamac, M.; Weidner, S. Antioxidative activity of phenolic fractions of pea (Pisum sativum). Czech J. Food Sci. 2001, 19, 139-142.

21. Kris-Etherton, P.M.; Hecker, K.D.; Bonanome, A.; Coval, S.M.; Binkoski, A.E.; Hilpert, K.F. Bioactive compounds in foods: Their role in the prevention of cardiovascular disease and cancer. Am. J. Med. 2002, 113, 71S-88S.

22. Kushi, L.H.; Meyer, K.A.; Jacobs, D.R. Cereals, legumes, and chronic disease risk reduction: Evidence from epidemiological studies. Am. J. Clin. Nutr. 1999, 70, 451S-458S.

23. Amarowicz, R.; Karamac, M.; Kmita-Glazewska, H.; Troszynska, A.; Kozlowska, H. Antioxidant activity of phenolic fractions of everlasting pea, faba bean and broad bean. J. Food Lipids 1996, 3, 199-211.

24. Amarowicz, R.; Naczk, M.; Zadernowski, R.; Shahidi, F. Antioxidative activity of condensed tannins of beach pea, canola hulls, evening primrose, and faba bean. J. Food Lipids 2000, 7, 195-205. 
25. Amarowicz, R.; Karamac, M.; Shahidi, F. Antioxidative activity of phenolic fractions of lentil (Lens culinaris). J. Food Lipids 2003, 10, 1-10.

26. Amarowicz, R.; Troszynska, A.; Pegg, R.B. Antioxidative and radical scavenging effects of phenolics from (Vicia sativum). Fitoterapia 2008, 79, 121-122.

27. Zia-Ul-Haq, M.; Cavar, S.; Qayum, M.; Imran, I.; de Feo, V. Compositional studies, antioxidant and antidiabetic activities of Capparis decidua (Forsk.) Edgew. Int. J. Mol. Sci. 2011, 12, 8846-8861.

28. Hochestein, P.; Atallah, A.S. The nature of oxidant and antioxidant systems in the inhibition of mutation and cancer. Mutat. Res. 1988, 202, 363-375.

29. Manian, R.; Anusuya, N.; Siddhuraju, P.; Manian, S. The antioxidant activity and free radical scavenging potential of two different solvent extracts of Camellia sinensis (L.) O. Kuntz, Ficus bengalensis L. and Ficus racemosa L. Food Chem. 2008, 107, 1000-1007.

30. Babu, B.H.; Shylesh, B.S.; Padikkala, J. Antioxidant and hepatoprotective effect of Alanthus icicifocus. Fitoterapia 2001, 72, 272-277.

31. Zia-Ul-Haq, M.; Shahid, S.A.; Ahmad, S.; Qayum, M.; Khan, I. Antioxidant potential of various parts of Ferula assafoetida L. J. Med. Plant. Res. 2012, 6, 3254-3258.

32. Yoshiki, Y.; Sirakura, T.; Okuda, K.; Okubo, K.; Sakabe, T.; Ngoya, I.; Ta-Mura, N. Hydrophilic Oxygen Radical Scavengers in the Leguminous Seeds and Derived Foods. In Agri-Food Quality. An Interdisciplinary Approach; Fenwick, G.R., Hedley, C., Richards, R.L., Khokahr, S., Eds.; The Royal Society of Chemistry: Cambridge, UK, 1996; pp. 360-365.

33. Raab, B.; Hempel, J.; Bohm, H. Antioxidtive and Antigenotoxic Properties of Flavonoids Prevailing in Vegetable. In Agri-Food Quality. An Interdisciplinary Approach; Fenwick, G.R., Hedley, C., Richards, R.L., Khokahr, S., Eds.; The Royal Society of Chemistry: Cambridge, UK, 1996; pp. 369-371.

34. Amarowicz, R.; Raab, B. Antioxidative activity of leguminous seed extracts evaluated by chemiluminescence methods. Z. Naturforsch. 1997, 52c, 709-712.

35. Ariga, T.; Hamano, M. Radical scavenging action and its mode in procyanidins B-1 and B-3 from adzuki beans to peroxyl radicals. Agric. Biol. Chem. 1990, 54, 2499-2504.

36. Zieliński, H. Peroxyl radical-trapping capacity of germinated legume seeds. Nahrung 2002, 46, 100-104.

37. Zhou, K.; Yu, L. Total phenolic contents and its antioxidant properties of commonly consumed vegetables grown in Colorado. LWT-Food Sci. Technol. 2006, 39, 1155-1162.

38. Troszyńska, A.; Kubicka, E. Superoxide scavenging activity of seed coat extracts from legume seeds. Pol. J. Food Nutr. Sci. 2001, 10, 55-59.

39. Singleton, C.L.; Rossi, J.A. Colorimetry of total phenolics with phosphomolybdic-phosphotungstic acid reagents. Am. J. Enol. Viticult. 1965, 16, 144-158.

40. Heimler, D.; Vignolini, P.; Dini, M.G.; Romani, A. Rapid tests to assess the antioxidant activity of Phaseolus vulgaris L. dry bean. J. Agric. Food Chem. 2005, 53, 3053-3056.

41. Xu, B.J.; Chang, S.K.C. A comparative study on phenolic profiles and antioxidant activities of legumes as affected by extraction solvents. J. Food Sci. 2007, 72, S159-S166.

42. Broadhurst, R.B.; Jones, W.T. Analysis of condensed tannins using acidified vanillin. J. Sci. Food Agric. 1978, 29, 788-794. 
43. Crozier, A.; Jensen, E.; Lean, M.E.I.; McDonald, M.S. Quantitative analysis of flavonoids by reverse-phase high performance liquid chromatography. J. Chromatogr. A 1997, 761, 315-321.

44. Chen, C.W.; Ho, C.T. Antioxidant properties of polyphenols extracted from green and black teas. J. Food Lipids 1995, 2, 35-46.

45. Benzie, I.F.F.; Strain, J.J. Ferric reducing/antioxidant power assay: Direct measure of total antioxidant activity of biological fluids and modified version for simultaneous measurement of total antioxidant power and ascorbic acid concentration. Methods Enzymol. 1999, 299, 15-27.

46. Wu, X.L.; Beecher, G.R.; Holden, J.M.; Haytowitz, D.B.; Gebhardt, S.E.; Prior, R. Lipophilic and hydrophilic antioxidant capacities of common foods in the United States. J. Agric. Food Chem. 2004, 52, 4026-4037.

47. Prior, R.L.; Hoang, H.; Gu, L.W.; Wu, X.L.; Bacchiocca, M.; Howard, L.; Hampsch-Woodill, M.; Huang, D.J.; Ou, B.X.; Jacob, R. Assay for hydrophilic and lipophilic antioxidant capacity (oxygen radical absorbance capacity (ORACFL) of plasma and other biological and food samples. J. Agric. Food Chem. 2003, 51, 3273-3279.

48. Ghiselli, A.; Serafini, M.; Maiani, G.; Azzini, E.; Ferro-Luzzi, A. A fluorescence-based method for measuring total plasma antioxidant capability. Free Radic. Biol. Med. 1995, 18, 29-36.

49. Halliwell, B.; Gutteridge, J.M.C.; Amoma, O.L. The deoxyribose method: a simple test tube assay for the determination of rate constant for reaction of hydroxyl radical. Anal. Biochem. 1987, 165, 215-219.

50. Sabu, M.C.; Ramadasan, K. Anti-diabetic activity of medicinal plants and its relationship with their antioxidant property. J. Ethanopharmacol. 2002, 81, 155-160.

51. Marcocci, L.; Maguire, J.J.; Droy, M.T. The nitric oxide scavenging properties of Gingo biloba extract EGb 761. Biochem. Biophys. Res. Commun. 1994, 15, 748-755.

52. Osawa, T.; Namiki, M. A novel type of antioxidant isolated from leaf wax of eucalyptus leaves. Agric. Biol. Chem. 1981, 45, 735-739.

53. Yen, G.C.; Duh, P.D. Scavenging effect of methanolic extracts of peanut hulls on free-radical and active-oxygen species. J. Agric. Food Chem. 1994, 42, 629-632.

Sample Availability: Not available.

(C) 2013 by the authors; licensee MDPI, Basel, Switzerland. This article is an open access article distributed under the terms and conditions of the Creative Commons Attribution license (http://creativecommons.org/licenses/by/3.0/). 